\title{
APROPRIAÇÃO DA TEORIA DAS REPRESENTAÇÕES SOCIAIS PELO CAMPO ACADÊMICO/CIENTÍFICO DA EDỦCAÇÃO FÍSICA NO BRASIL: O ESTADO DO CONHECIMENTO (2004-2016) ${ }^{1}$
}

\author{
Diego Petyk de Sousa \\ Universidade Estadual de Ponta Grossa, Ponta Grossa, Paraná, Brasil \\ Érica Fernanda de Paula \\ Universidade Estadual de Ponta Grossa, Ponta Grossa, Paraná, Brasil \\ Constantino Ribeiro de Oliveira Junior \\ Universidade Estadual de Ponta Grossa, Ponta Grossa, Paraná, Brasil \\ Alfredo Cesar Antunes \\ Universidade Estadual de Ponta Grossa, Ponta Grossa, Paraná, Brasil
}

\begin{abstract}
Resumo
O objetivo deste estudo foi identificar a apropriação da Teoria das Representações Sociais pelo campo acadêmico/científico da educação física brasileira entre os anos de 2004 a 2016. Para tanto, procede-se à coleta de dados nos periódicos classificados entre A2 a B2 da área 21 no Webqualis. Para auxiliar a construção de critérios de inclusão e exclusão de artigos, utilizaram-se os procedimentos metodológicos da Análise de Conteúdo, chegando a um Corpus de análise de 11 artigos. As categorias de análise foram: vínculo institucional; formação profissional; estrutura metodológica; construção do objeto de pesquisa em Representações Sociais. Constatou-se predominância de: produção no Sudeste; autores oriundos da educação física; opção por abordagens qualitativas; e utilização das obras de Moscovici como referencial teórico.
\end{abstract}

Palavras-chave: Educação Física. Representação Social. Representações Sociais. Conhecimento.

\section{APPROPRIATION OF THE THEORY OF SOCIAL REPRESENTATIONS BY THE ACADEMICSCIENTIFIC FIELD OF PHYSICAL EDUCATION IN BRAZIL: THE STATE-OF-THE-ART (2004-2016)}

\begin{abstract}
The objective of this study was to identify the appropriation of the Theory of Social Representations by the academic/scientific field of physical education in Brazil between 2004 and 2016. For this purpose, the data were collected in journals classified as A1 to B2 of area 21 in Webqualis. To assist the criteria of inclusion and exclusion of the articles, the methodological procedures of Content Analysis were used, reaching a corpus of analysis of 11 articles. The categories of analysis were: institutional link, professional qualification, methodological structure, and construction of the research subject in Social Representations. The main features found were: production in the Southeast; authors belonging to the physical education
\end{abstract}

\footnotetext{
${ }^{1} \mathrm{O}$ presente trabalho não contou com o apoio financeiro de nenhuma natureza para sua realização.
} 
area; option for the qualitative approaches, and use of Moscovici's works as theoretical background.

Keywords: Physical Education. Social Representation. Social Representations. Knowledge.

\section{APROPIACIÓN DE LA TEORÍA DE LAS REPRESENTACIONES SOCIALES POR EL CAMPO ACADÉMICO/CIENTÍFICO DE LA EDUCACIÓN FÍSICA EN BRASIL: EL ESTADO DEL CONOCIMIENTO (2004-2016)}

\section{Resumen}

El objetivo de este estudio ha sido identificar la apropiación de la Teoría de las Representaciones Sociales por el campo académico/científico de la educación física brasileña entre los años de 2004 a 2016. Se han utilizado los procedimientos de análisis de contenido. Se han buscado artículos en periódicos con clasificación del Qualis de educación física, disponible en el Webqualis del último cuadrienio, entre los estratos A2 a B2, el corpus de análisis se ha delimitado a 11 artículos. Las categorías de análisis han sido: vínculo institucional; formación profesional; estructura metodológica; construcción del objeto de investigación en Representaciones Sociales. Se ha constatado el predominio de: producción en el Sudeste; autores oriundos de la educación física; opción por abordajes cualitativas; y utilización de las obras de Moscovici como referencial teórico.

Palabras clave: Educación Física. Representación Social. Representaciones Sociales. Conocimiento.

\section{Introdução}

A noção ${ }^{2}$ de campo é descrita por Bourdieu (1996; 2003) como sendo um espaço social onde há lutas no seu interior, no qual os agentes se enfrentam, com meios e fins diferenciados, segundo a sua posição na estrutura do campo de forças, contribuindo assim para a conservação ou a transformação de sua estrutura.

De tal modo, por meio dessa contribuição da teoria bourdieusiana é possível compreender a lógica de diferentes campos e os seus objetos em disputa. O campo acadêmico/científico é um espaço onde os objetos em disputa pelos agentes (cientistas) de uma determinada área do conhecimento são a legitimidade e as concepções de como deve ser a ciência. Alguns dos elementos que permitem identificar essa disputa são os periódicos acadêmicos, responsáveis pela divulgação do conhecimento científico.

No caso deste estudo, os elementos que permitem identificar essa disputa são os periódicos acadêmicos da área de Educação Física. Essa característica do campo acadêmico/científico da Educação Física brasileira é identificada por Lazzarotti Filho, Silva e Mascarenhas (2014). Além dos periódicos, outros elementos em disputa são as bolsas de estudo, os financiamentos para pesquisa, as representações de áreas, e a coordenação de programas de pós-graduação.

Para Gutierrez, Almeida e Marques (2016), o núcleo duro e original de pesquisa em Educação Física está preocupado com questões como a preparação para atividade física, a interface entre exercício físico e busca pela saúde e as práticas esportivas. Porém, existe um movimento de apropriação pela área de conhecimentos oriundos das Ciências Humanas (Ci-

\footnotetext{
${ }^{2}$ Para Hardy-Vallée (2013) os conceitos científicos são na verdade teorias, mas não são estritamente mentais, já que estão distribuídos também de forma escrita. Quando se refere a tais conceitos, o adequado é a utilização do termo "noção" e reserva-se o termo "conceito" para as particularidades mentais que cada indivíduo manipula, sem considerar o rigor científico, pois um indivíduo pode possuir um conceito sem que isso implique que ele tenha um conceito exato.
} 
ências Sociais, Filosofia, História, Geografia, Educação, Psicologia, Linguística, Direito, Administração, Economia, Contabilidade e Arquitetura), sendo essa apropriação maior com algumas áreas, como é o caso da Sociologia.

Essa apropriação também pode ser entendida como interdisciplinaridade, que para Japiassu (1976, p. 75) "[...] [se] caracteriza pela intensidade das trocas entre especialistas e pelo grau de integração real das disciplinas, no interior do projeto específico de pesquisa". Ou seja, a relação entre a Educação Física e as Humanidades é estabelecida visando expandir a própria área, através da apropriação de teorias e métodos de uma área estabelecida. Um dos movimentos de apropriação pode ser entre Educação Física e Psicologia, especificamente a Teoria das Representações Sociais (TRS), que está presente na Psicologia Social.

Quem inaugurou essa corrente teórica, e a utilização do termo Representação Social, foi Serge Moscovici, para nominar o tipo de fenômeno interpretado por sua teoria, porém o autor sempre relutou em conceituar a teoria, logo a definição mais conhecida no campo acadêmico/científico é a de Jodelet (2001, p. 22), para quem as Representações Sociais são "uma forma de conhecimento, socialmente elaborada e partilhada, com um objetivo prático, e que contribui para a construção de uma realidade comum a um conjunto social."

Diante dessa contextualização, a questão norteadora do presente estudo foi: como está sendo feita a apropriação da Teoria das Representações Sociais pelo campo acadêmico/científico da Educação Física brasileira? Portanto, o objetivo do presente estudo delimitouse em identificar a apropriação da Teoria das Representações Sociais (TRS) pelo campo acadêmico/científico da Educação Física brasileira entre os anos de 2004 a 2016.

A presente pesquisa deseja contribuir para os pesquisadores iniciantes na TRS inseridos no campo acadêmico/científico da Educação Física brasileira, com os elementos teóricos e metodológicos identificados por meio do estado do conhecimento. Dessa forma, objetiva-se subsidiar futuros trabalhos interdisciplinares, visando o avanço qualitativo e quantitativo das produções vinculadas à TRS, pelo campo acadêmico/científico da Educação Física brasileira.

\section{Metodologia}

Por metodologia entende-se, conforme Minayo (2012), o caminho do pensamento e a prática exercida em uma pesquisa. Dessa forma, esta pesquisa foi classificada com base nos apontamentos de Gil (2008).

Inicialmente, trata-se de uma pesquisa de natureza qualitativa, com características de uma pesquisa exploratória, pois visa identificar o uso da TRS pelos pesquisadores que publicam em periódicos da área de Educação Física com o foco e escopo em pesquisas de cunho sociocultural (Ciências Sociais e Humanas). Dessa forma demonstra-se uma visão geral da apropriação da TRS pelo campo acadêmico/científico da Educação Física brasileira.

Na questão do delineamento, utilizaram-se os recursos da pesquisa bibliográfica, especialmente o estado do conhecimento, que é entendido como de caráter bibliográfico, em que, principalmente, trabalha-se apenas com um setor das publicações, objetivando o mapeamento de certa produção acadêmica em determinado ou diferentes campos do conhecimento. (FERREIRA, 2002; ROMANOWSKI; ENS, 2006).

Para compor este estado do conhecimento sobre TRS no campo acadêmico/científico da Educação Física brasileira, a seleção dos artigos seguiu os procedimentos da análise de conteúdo de Bardin (2011). Assim, delimitaram-se seis filtros como critérios de inclusão e exclusão dos artigos. Sendo filtros de inclusão: filtro1 - seleção dos periódicos; filtro 2 - busca por meio de termos indexadores; filtro 3 - recorte temporal. E os de exclusão: filtro 4 ensaios; filtro 5 - utilização do termo Representações Sociais (RS) sem vinculação com a TRS; filtro 6 - texto sem delimitação sujeito e objeto. 
No filtro 1 foram selecionados os periódicos nacionais voltados a publicar pesquisas científicas sobre os temas de Educação Física e esporte - com a classificação do Qualis da área de Educação Física que está presente na área de avaliação 21, disponível no Webqualis quadriênio 2013-2016, entre A2 a B2 - que disponibilizam no seu foco e escopo espaço para pesquisas de cunho sociocultural. Assim, chegou-se aos seguintes periódicos apresentados no Quadro 1.

Quadro 1 - Periódicos nacionais voltados a publicações de pesquisas científicas sobre os temas de Educação Física e esporte - com a classificação do Qualis da área de Educação Física que está presente na área de avaliação 21, disponível no Webqualis quadriênio 2013-2016, entre A2 a B2 - que disponibilizam no seu foco e escopo espaço para pesquisas de cunho sociocultural.

\begin{tabular}{|c|c|}
\hline Nome do Periódico & Qualis na área de Educação Física \\
\hline Movimento & A2 \\
\hline Journal of Physical Education/Revista da Educação Física & B1 \\
\hline Revista Motriz & B1 \\
\hline Revista Brasileira de Ciências do Esporte (RBCE) & B1 \\
\hline Revista Brasileira de Educação Física e Esporte (RBEFE) & B1 \\
\hline Licere & B2 \\
\hline Motrivivência & B2 \\
\hline Pensar a Prática & B \\
\hline
\end{tabular}

Fonte: Elaborado pelos autores, 2018.

No filtro 2 foram necessários o acesso a cada periódico e a realização de busca no campo pesquisa por meio dos termos indexadores e título das expressões: Representações Sociais e Representação Social. Após essa busca o periódico LICERE foi excluído da composição do corpus de análise, pois não apresentava artigos conforme o critério de inclusão supracitado.

O filtro 3 diz a respeito ao recorte temporal. O ano de 2004 foi estabelecido como ano inicial devido ao fato de que todos os periódicos disponibilizaram o seu acervo de modo online a partir desse ano; e como ano final, 2016 foi escolhido por ser o último ano completo em que todos os periódicos já publicaram as suas edições esperadas, de acordo com sua periodicidade.

Chegou-se a 17 artigos publicados, que foram submetidos à leitura flutuante e submetidos aos filtros de exclusão. $\mathrm{O}$ filtro 4 diz respeito à não inclusão de ensaios no corpus de análise. Desse modo, dois artigos foram excluídos. O filtro 5 caracteriza-se pela coerência do termo RS sem a articulação com o significado teórico e conceitual, conforme Spink (1996). Com esse filtro excluíram-se três artigos. Por meio do filtro 6 excluiu-se um artigo por não estabelecer uma relação clara entre objeto e sujeito, segundo Sá (1998). Nesse último grupo de filtros foi excluído o artigo da Revista Movimento, a qual não fez parte da composição do corpus de análise do presente estado do conhecimento.

Portanto, após a verificação dos seis filtros o corpus de análise foi composto por 11 artigos, classificando-se progressivamente em T1, T2 e assim sucessivamente até T11. As categorias de análise foram criadas a priori, sendo elas: a) vínculo institucional; b) formação profissional; c) estrutura metodológica; d) construção do objeto de pesquisa em Representações 
Sociais. As subcategorias destas categorias foram emergindo ao longo da análise e interpretação dos dados, e foram descritas nos resultados e discussão.

\section{Resultados e discussão}

A partir da busca dos artigos publicados entre os anos de 2004 a 2016, no campo acadêmico/científico da Educação Física brasileira sobre a TRS e da seleção a partir dos filtros, restaram onze artigos, que compuseram o corpus de análise, os quais estão apresentados no quadro a seguir.

Quadro 2 - Corpus de análise: artigos publicados entre os anos de 2004 a 2016, no campo acadêmico/científico da educação física brasileira sobre a TRS.

\begin{tabular}{|c|c|c|c|}
\hline Texto & Citação & Título & Periódico \\
\hline $\mathrm{T} 1$ & $\begin{array}{l}\text { Molina; Silva e } \\
\text { Silveira (2004) }\end{array}$ & $\begin{array}{l}\text { Celebração e transgressão: a representação do esporte } \\
\text { na adolescência }\end{array}$ & $\begin{array}{l}\text { Revista Brasileira de } \\
\text { Educação Física e Es- } \\
\text { portes }\end{array}$ \\
\hline $\mathrm{T} 2$ & $\begin{array}{l}\text { Valentin e Coelho } \\
\text { (2005) }\end{array}$ & $\begin{array}{l}\text { Sobre as escolinhas de futebol: processo civilizador e } \\
\text { práticas pedagógicas }\end{array}$ & Motriz \\
\hline $\mathrm{T} 3$ & $\begin{array}{l}\text { Espírito-Santo e } \\
\text { Mourão (2006) }\end{array}$ & $\begin{array}{l}\text { A auto-representação da saúde dos professores de Edu- } \\
\text { cação Física de Academias }\end{array}$ & $\begin{array}{l}\text { Revista Brasileira de } \\
\text { Ciência do Esporte }\end{array}$ \\
\hline $\mathrm{T} 4$ & $\begin{array}{l}\text { Beggiato e Silva } \\
(2007)\end{array}$ & $\begin{array}{l}\text { Educação Física Escolar no ciclo II do ensino funda- } \\
\text { mental: aspectos valorizados }\end{array}$ & Motriz \\
\hline T5 & $\begin{array}{l}\text { Pereira e Mazzotti } \\
(2008)\end{array}$ & $\begin{array}{l}\text { Representações sociais de Educação Física por alunos } \\
\text { trabalhadores do ensino noturno }\end{array}$ & Motriz \\
\hline T6 & Retondar (2009) & $\begin{array}{l}\text { As Representações Sociais do Ato Pedagógico dos pro- } \\
\text { fessores de Educação Física que atuam no Ensino Fun- } \\
\text { damental no Municipio do Rio de Janeiro }\end{array}$ & Motrivivência \\
\hline $\mathrm{T} 7$ & $\begin{array}{l}\text { Assunção; Assis e } \\
\text { Campos (2012) }\end{array}$ & $\begin{array}{l}\text { Belos, Sadios e normais: as Representações Sociais dos } \\
\text { corpos infantis na Revista Pais \& Filhos (1968-1977). }\end{array}$ & $\begin{array}{l}\text { Revista Brasileira de } \\
\text { Ciência do Esporte }\end{array}$ \\
\hline $\mathrm{T} 8$ & Mello et al. (2012) & $\begin{array}{l}\text { Representações Sociais sobre a Educação Física na } \\
\text { Educação Infantil }\end{array}$ & $\begin{array}{l}\text { Journal of Physical } \\
\text { Education }\end{array}$ \\
\hline T9 & $\begin{array}{l}\text { Osório; Assis e } \\
\text { Pereira (2013) }\end{array}$ & $\begin{array}{l}\text { A representação social de estudantes de Educação Físi- } \\
\text { ca sobre o campo profissional }\end{array}$ & Pensar a Prática \\
\hline $\mathrm{T} 10$ & Silva et al. (2014) & $\begin{array}{l}\text { Representações sociais de adolescentes sobre ser saudá- } \\
\text { vel }\end{array}$ & $\begin{array}{l}\text { Revista Brasileira de } \\
\text { Ciência do Esporte }\end{array}$ \\
\hline $\mathrm{T} 11$ & $\begin{array}{l}\text { Vasconcelos } \\
\text { Campos (2014) }\end{array}$ & $\begin{array}{l}\text { Ancoragem da Representação Social da Educação Físi- } \\
\text { ca Escolar nas abordagens teóricas da Educação Física }\end{array}$ & Motrivivência \\
\hline
\end{tabular}

Fonte: Elaborado pelos autores, 2018.

Os resultados encontrados estão apresentados no Quadro 3, o qual ilustra o número de artigos publicados durante os anos de 2004 até 2016, nos respectivos periódicos, e a pro- 
dução sobre Representações Sociais, entre parênteses. Além disso, é apresentado o número total de artigos por periódico durante o ano e no total.

Quadro 3 - Número geral de artigos publicados em periódicos brasileiros sobre Educação Física e esportes que disponibilizam no seu foco e escopo espaço para pesquisas de cunho sociocultural, e publicaram sobre Represen-

\begin{tabular}{|c|c|c|c|c|c|c|c|}
\hline & MOTRIZ & RBCE & RBEFE & REFUEM & MOTRIV. & $\begin{array}{l}\text { PENSAR A PRÁTI- } \\
\text { CA }\end{array}$ & $\begin{array}{l}\text { TOTAL (por } \\
\text { ano) }\end{array}$ \\
\hline 2004 & 24 & 31 & $31(1)$ & 19 & 22 & 16 & $143(1)$ \\
\hline 2005 & $24(1)$ & 33 & 29 & 24 & 20 & 15 & 145 (1) \\
\hline 2006 & 34 & $35(1)$ & 29 & 24 & 19 & 19 & $160(1)$ \\
\hline 2007 & $37(1)$ & 39 & 28 & 23 & 18 & 21 & $166(1)$ \\
\hline 2008 & $50(1)$ & 37 & 28 & 60 & 40 & 30 & $245(1)$ \\
\hline 2009 & 105 & 40 & 35 & 61 & $22(1)$ & 36 & $299(1)$ \\
\hline 2010 & 112 & 61 & 48 & 60 & 34 & 41 & $356(0)$ \\
\hline 2011 & 76 & 67 & 73 & 60 & 32 & 46 & $354(0)$ \\
\hline 2012 & 77 & $62(1)$ & 63 & $60(1)$ & 37 & 64 & $363(2)$ \\
\hline 2013 & 97 & 67 & 60 & 60 & 37 & $75(1)$ & $396(1)$ \\
\hline 2014 & 60 & $61(1)$ & 60 & 60 & $41(1)$ & 79 & $361(2)$ \\
\hline 2015 & 55 & 53 & 54 & 60 & 49 & 62 & $333(0)$ \\
\hline 2016 & 62 & 54 & 60 & 60 & 57 & 72 & $365(0)$ \\
\hline Total & $813(3)$ & $640(3)$ & $598(1)$ & $631(1)$ & $428(2)$ & $576(1)$ & $3686(11)$ \\
\hline
\end{tabular}

Fonte: Elaborado pelos autores, 2018.

Nota: textos indicados como ensaios não contaram na soma.

Nos 13 anos pesquisados (2004-2016), foram identificados 11 artigos, o que representa a média de 0,85 artigos por ano. Até o ano de 2009 foram publicados seis artigos, sendo observada a regularidade de um artigo por ano, independentemente do periódico. Porém, desde 2010 há uma oscilação entre momentos de publicação e ausência, estando concentrados os demais cinco artigos nos anos de 2012, 2013 e 2014.

Nesse sentido, é possível identificar que atualmente não há regularidade, nem mesmo um crescimento progressivo das produções relacionadas às TRS, tendo em vista que em 2015 e 2016 nenhum texto foi encontrado dentre os periódicos analisados. Pode-se inferir que os pesquisadores da área poderiam ter migrado as suas publicações que usam da TRS para periódicos de outras áreas.

Em relação à região a que estão vinculados os autores dos artigos, foi observada a predominância de $81,81 \%$ da região Sudeste, sendo que apenas o T1 (região Sul) e o T10 (região Nordeste) fogem à regra. Entre as Instituições de Ensino Superior (IES) da região Sudeste aparece: Universidade Estadual Paulista (T2); Universidade Gama Filho (T3, T8 e T9); Universidade São Judas Tadeu e Centro Universitário Fieo (T4); Universidade Estácio de Sá (T5 e T11); Universidade Estadual do Rio de Janeiro (T6 e T11); Universidade Federal de Minas Gerais (T7); Universidade Federal do Espírito Santo e Rede de Ensino Doctum (T8); 
Universidade Souza Marques (T11). Na região Sul, a Universidade do Vale do Rio dos Sinos (T1); e no Nordeste, a Universidade Estadual do Sudoeste da Bahia (T10).

Entre as instituições supracitadas há públicas e privadas. Nos onze artigos analisados, prevaleceu a presença de IES privadas $(45,45 \%$, T1, T3, T4, T5 e T9), seguidas pelas IES públicas $(36,36 \%$, T2, T6, T7 e T10), e por algumas parcerias entre IES públicas e privadas (18,18\%, T8 e T11). A predominância da região Sudeste no campo acadêmico/científico da Educação Física brasileira em relação ao uso da TRS é diferente do que foi descrito por Almeida (2009).

A entrada da TRS no Brasil aconteceu na década de 1980, por brasileiros que frequentaram a École de Hautes Études em Sciences Sociales, onde ao longo dos anos de 1970 cursaram disciplinas com Serge Moscovici e Denise Jodelet. Em seu retorno ao Brasil, esses pesquisadores brasileiros foram inserindo-se em universidades situadas fora do eixo Rio-São Paulo, em regiões consideradas periféricas em relação à produção científica. Porém, como se identificou no campo acadêmico/científico da Educação Física brasileira, a predominância está na região Sudeste e especialmente no estado do Rio de Janeiro.

Pode-se inferir que essa concentração está ligada ao fato do contato direito de Moscovici e Jodelet com o Rio de Janeiro, por meio de cursos, eventos e palestras nos anos 90 do século XX e anos 2000 (JODELET, 2011), influenciando diversos pesquisadores iniciantes. Estes, por sua vez, foram se inserindo no campo acadêmico/científico e formando novos grupos de estudos em TRS, facilitando a divulgação da TRS no Brasil. Em algum momento da formação acadêmica dos 31 autores que aparecem nesse estudo, eles ou seus orientadores tiveram contato direito ou indireto com esses grupos de pesquisadores.

$\mathrm{Na}$ categoria formação profissional, foram levantados no currículo do sistema Lattes o nível e o tipo de formação dos 31 autores dos artigos analisados. Dessa forma, 16 são graduados apenas em Educação Física, três em Enfermagem, três em Psicologia. Com um representante: Comunicação Social, Fisioterapia, Letras, e Pedagogia. Com dupla formação: Educação Física/Pedagogia, Educação Física/Geografia, Educação Física/Psicologia. Não foi encontrado o currículo Lattes de dois autores.

Referente à maior formação atual, 20 têm formação em nível de doutorado - sete em Educação Física, seis na Educação, dois em Enfermagem. Com um representante: Ciências do Movimento Humano, Filosofia e Ciências da Educação, Letras, e Psicologia. Uma autora tem doutorado em duas áreas distintas - História e Sociologia. Ademais, sete são mestres, três em Educação física, dois em Enfermagem e Saúde, um em Educação e um em Saúde Pública.

Pode-se identificar uma predominância de pesquisadores com a área de formação inicial em Educação Física que, no entanto, ao longo de sua formação foram buscando o diálogo com outras áreas. Isso pode ser reflexo do caráter multidisciplinar e interdisciplinar das pesquisas com base na TRS.

No caso da área de Educação Física, Gutierrez, Almeida e Marques (2016) explicam que o diálogo entre a área de Educação Física e as Ciências Humanas acontece visando a adoção de recursos teóricos e metodológicos da segunda para expandir a primeira. Assim, esse movimento entre a área de Educação Física e a TRS da Psicologia pode ser uma contribuição para o avanço de possibilidades em estudos na área de Educação Física.

A respeito da categoria estrutura metodológica dos artigos encontrados, buscou-se identificar os apontamentos dos autores referentes às subcategorias abordagem do problema, objetivo de pesquisa, nível de pesquisa, delineamento, instrumentos utilizados na coleta de dados, e técnicas de análise e interpretação dos dados.

Quanto à abordagem do problema, o artigo T9 apresenta-se como estudo quantitativo, sendo os demais artigos $(90,90 \%)$ estudos qualitativos. Para Sá (1998), no aspecto de preferência de métodos qualitativos ou quantitativos no uso dos estudos de TRS, não existe um método preferencial. Contudo, em uma apresentação sintética, poderíamos colocar que estu- 
dos com base em Moscovici e Jodelet correspondem a métodos qualitativos, já estudos com base em Abric e Doise estariam mais próximos dos métodos quantitativos. Porém, a TRS permite a articulação metodológica para modelos plurais.

De maneira geral, Moscovici (1995, p. 14) deixa claro a importância e a necessidade da pluralidade de métodos: "sou fundamentalmente contra a tendência de fetichizar um método específico.", pois, segundo o autor, "a Teoria das Representações Sociais, mesmo que isso possa suscitar resistências ou discordâncias entre nós, permanecerá criativa por tão longo tempo, o quanto ela souber aproveitar as oportunidades que cada método disponível possa oferecer".

Portanto, a partir da constatação da predominância de uso de métodos qualitativos nos estudos de TRS no campo acadêmico/científico da Educação Física brasileira, pode-se inferir a necessidade de avançar na pluralidade de métodos, permitindo a criação de novos olhares frente às futuras pesquisas.

$\mathrm{Na}$ subcategoria níveis de pesquisa foi identificado que os 11 artigos analisados se encontram caracterizados como descritivos. Destes, três adquirem o nível exploratóriodescritivo (T7, T10, T11). Para Gil (2008) a pesquisa exploratória permite ao investigador aumentar seu conhecimento sobre determinado problema. Já a pesquisa descritiva é voltada para a pormenorização de determinada população ou fenômeno.

Assim, os três artigos que se identificaram como exploratório-descritivos buscaram a articulação de forma complementar entre esses níveis de pesquisa. Dessa forma, a etapa exploratória foi utilizada para conhecer o contexto de inserção de determinado fenômeno de representação social, já o momento de descrição buscou o detalhamento e explicação dos fenômenos de representação social pesquisados.

Referente à subcategoria delineamento, 90,90\% (T1, T2, T3, T4, T5, T6, T8, T9, T10 e T11) utilizaram de fonte de dados fornecida por pessoas, exemplos foram: estudo de campo, estudo de caso e levantamento survey. Além desses, há um estudo exclusivamente documental (T7).

Para Gil (2008) existe uma diversidade de delineamentos de pesquisa. Em geral, eles servem para auxiliar os pesquisadores na solução de problemas e no direcionamento da escolha dos instrumentos de coletas de dados.

Como característica das pesquisas com uso da TRS, os problemas formulados estão voltados para aspectos do cotidiano. Tal característica ficou evidente nos artigos analisados, pois em sua maioria utilizaram informações coletadas com indivíduos, sobre aspectos presentes no seu cotidiano. Assim, a predominância de delineamentos evidenciados no campo acadêmico/científico da Educação Física brasileira, em relação aos artigos levantados, é coerente com o arcabouço teórico-metodológico da TRS.

Em relação à subcategoria coleta de dados, observa-se a utilização de diferentes instrumentos, sendo a utilização de questionários ou entrevistas a opção predominante em $90,90 \%$ dos casos, não tendo sido utilizados apenas no T7, que empregou exclusivamente o registro documental. Essa informação é coerente com o evidenciado na subcategoria delineamento.

Dos artigos estudados, utilizaram-se somente de entrevista semiestruturada: T2 e T10; questionário aberto: T4 e T6; questionário fechado: T11; e evocações: T9. Outra característica encontrada foi o recurso da triangulação de dados. No estudo T1 a triangulação de dados foi entre registro documental, entrevista semiestruturada e observação simples. O T3 utilizou de questionário fechado e entrevista semiestruturada. Já os T5 e T8 se utilizaram de entrevista semiestruturada e observação simples.

Para a análise dos dados foram utilizadas diferentes estratégias. Dos trabalhos analisados, 27,27\% utilizaram Análise de Conteúdo (T3, T4 e T10); 18,18\%, Análise Estatística 
(T9 e T11); 18,18\%, Análise de Discurso (T2 e T6); 18,18\%, Análise Interpretativa (T1 e T7); 9,09\%, Análise retórica do corpus discursivo (T5); e 9,09\%, Análise crítica do discurso (T8).

Mesmo que a TRS não privilegie um modelo único de caminho metodológico, Sá (1998) destaca que a forma mais comum de pesquisa em RS articula a coleta de dados por meio de entrevistas com a técnica de análise de conteúdo.

Foi identificado no campo acadêmico/científico da Educação Física brasileira que o uso de entrevista é predominante. Já na questão das técnicas de análise ocorreu uma maior diversificação. Mesmo assim, a forma comum descrita por Sá (1998) ainda continua privilegiada no campo. Porém, o campo está buscando novas formas de analisar os dados. Isso reforça a ideia de Moscovici (1995) da necessidade de buscar novos olhares e recursos para as pesquisas em TRS.

Partindo da taxonomia de Bloom, com o intento de identificar o que os artigos têm buscado, foram classificados os verbos empregados nos objetivos dos artigos de acordo com as categorias do domínio cognitivo: 1. Conhecimento, 2. Compreensão, 3. Aplicação, 4. Análise, 5. Síntese, 6. Avaliação. (FERRAZ; BELHOT, 2010). Percebeu-se que os estudos encontrados buscam principalmente conhecer $(45,45 \%$, T5, T6, T8, T10 e T11) e compreender (36,36\%, T1, T2, T3 e T7) as Representações Sociais. Dos demais, um artigo $(9,09 \%$, T9) buscou o domínio cognitivo de análise, e outro $(9,09 \%$, T4), avaliar.

Ao sintetizar o pensamento de Moscovici (1995; 2015) e Jodelet (1989), pode-se compreender que as Representações Sociais são conteúdos do pensamento cotidiano, elaborados socialmente e por meio de trocas comunicativas que podem contribuir para a construção de uma realidade comum a determinado grupo social.

Para identificar essas características da TRS, o pesquisador busca conhecer e compreender a realidade social a partir de um determinado grupo social. Portanto, no design de pesquisa os objetivos que visam conhecer e compreender devem ser os mais adequados para atingir as expectativas da teoria. Logo, os resultados supracitados reforçam as características das Representações Sociais destacadas por Moscovici (1995; 2015) e Jodelet (1989).

A análise a partir desse momento estará centrada nas discussões de Sá (1998) e de Jodelet (2011) referentes à categoria construção do objeto de pesquisa em Representações Sociais. Assim, os resultados foram divididos em três subcategorias: a) objeto de representação social; b) temáticas de estudo; c) fundamentação teórica.

Para identificar a subcategoria objeto de RS, o presente trabalho embasa-se nos pressupostos de Jodelet (2001), de que a preposição da TRS é sempre de alguém (o sujeito) e de alguma coisa (o objeto). Assim, na construção do objeto de pesquisa é preciso considerar a simultaneidade entre o sujeito e o objeto da representação estudada.

Sobre os sujeitos da pesquisa, a maioria era composta de professores, 45,45\%, (T2 professores das escolinhas de futebol, T3 professores de academia, T6 e T11 professores de educação física escolar, e T8 professores de um Centro de Educação Infantil), ou alunos (36,36\%, T1 alunos de um projeto social, T4 alunos escolares, T5 alunos da Educação de Jovens e Adultos e T9 alunos de graduação). O T10 (9,09\%) destaca como sujeitos alguns adolescentes, porém em idade escolar (Ensino Médio), e por fim o T7 $(9,09 \%)$ utiliza a Revista Pais \& Filhos como sujeito.

Com relação aos objetos, as práticas pedagógicas (36,36\%, T2, T6, T8 e T11) foram as mais estudadas. Outros objetos foram: Educação Física escolar (18,18\%, T4 e T5), campo e função do professor $(9,09 \%$, T9), corpo infantil $(9,09 \%$, T7), projeto social $(9,09 \%$, T1), saúde $(9,09 \%$, T3) e ser saudável $(9,09 \%$, T10).

Jodelet (2011), ao identificar características das pesquisas brasileiras sobre TRS, destaca a diversidade de produtos, porém, com finalidade comum em compreender a realidade social do país. Essa questão é diferente das europeias, que estão pautadas em avanços teóricos e metodológicos. Isso mostra uma tendência dos pesquisadores brasileiros em aplicar a teoria. 
Essas características podem ser evidenciadas para as pesquisas de RS na área de Educação Física, principalmente na preocupação em compreender o contexto escolar, seja por meio de profissionais, ou de alunos envolvidos na própria realidade estudada.

Entre os artigos, a temática que sobressai é a Educação $(63,63 \%$ T1, T2, T4, T5, T6, T8 e T11), seguida pela Saúde (27,27\% T3, T7 e T10) e Trabalho (9,09\%, T9). Essas temáticas também foram identificadas nos estudos de Sá (1998) e de Jodelet (2011) sobre TRS. Isso quer dizer que as temáticas pesquisadas na área de Educação Física não estão dissonantes dos estudos da TRS de outras áreas da comunidade científica brasileira.

No tocante ao referencial teórico dos artigos, a primeira observação a ser feita é que 90,90\% (10 artigos) utilizam alguma obra de Moscovici como referencial. Para Sá (1998) a grande teoria de Moscovici se desdobra em três correntes teóricas complementares: abordagem processual de Jodelet - mais fiel às proposições iniciais de Moscovici, abordagem estruturalista de Abric, e abordagem societal de Doise. Esses autores foram citados em seis artigos, Jodelet foi a mais utilizada, sendo mencionada em cinco artigos (T2, T3, T5, T9 e T10), Abric aparece em um (T11), já Doise não é citado nos artigos que foram mapeados.

O T6 entende representações a partir de Castoriadis (1982). Também fora da grande teoria de Moscovici, são citados Chartier (1990), pelo T2, e Rorty (1994), pelo T8, porém essas vertentes foram complementares à de Moscovici nos respectivos artigos.

Além das fontes primárias, foram citados outros autores ligados às Representações Sociais, principalmente Spink (T3, T4 e T8). Além dela, Guareschi e Jovchelovitch (T1), Coelho e Votre (T2) e Sá (T9). Tais autores foram utilizados principalmente como intérpretes de Moscovici.

Pode-se verificar como característica do campo acadêmico/científico da Educação Física brasileira a consulta ao autor base da grande teoria - Moscovici. Fato esse que pode estar ligado à recente origem da TRS - década de 60 do século XX - e às suas abordagens, que não abandonam os pressupostos iniciais de Moscovici.

\section{Considerações finais}

O presente estudo foi realizado com o intuito de identificar a apropriação da Teoria das Representações Sociais pelo campo acadêmico/científico da Educação Física brasileira entre os anos de 2004 a 2016. A partir da busca realizada nos periódicos brasileiros de Educação Física e esportes que disponibilizam no seu foco e escopo espaço para pesquisas de cunho sociocultural, o corpus da análise foi composto por 11 artigos.

Os resultados identificaram a predominância da região Sudeste, em contraposição a entrada da TRS pelas regiões periféricas, e o fato de que os autores buscaram ao longo de sua formação inicial e continuada a aproximação com outras áreas do conhecimento, possibilitando um iminente diálogo interdisciplinar nas suas pesquisas. Fato esse que demonstra a apropriação da TRS pelos pesquisadores da área de Educação Física.

Por se tratar de uma pesquisa exploratória, o presente estudo permite a visualização de problemáticas para pesquisas futuras. Identifica-se ausência de textos publicados nos periódicos analisados entre 2015 a 2016. Infere-se que devido à característica interdisciplinar os pesquisadores podem ter migrado para outras áreas, porém emerge a possibilidade de em estudos futuros analisarem-se teses e dissertações com o intuito de identificar se há produção sobre TRS e temáticas vinculadas à Educação Física em outras áreas do conhecimento.

Em relação à apropriação da TRS e seus aspectos metodológicos nos artigos estudados, evidenciou-se que os pesquisadores do campo acadêmico/científico da Educação Física brasileira estão alinhados com os pressupostos da TRS, principalmente pela característica de estudos que trabalham questões vivas, algo específico de pesquisadores brasileiros da TRS e diferente dos europeus. 
Por fim, o uso da TRS é pouco frequente no campo. Torna-se necessário aprofundar nas discussões tanto do referencial teórico, como na aplicação da teoria em estudos, principalmente no sentido de explorar as abordagens do núcleo central de Abric e a societal de Doise, visando novas interações para os estudos que perpassam o campo acadêmico/científico da Educação Física brasileira.

\section{Referências}

ALMEIDA, A. M. O. Abordagem societal das Representações Sociais. Sociedade e Estado, Brasília, v. 24, n. 3, p. 713-737, set./dez. 2009. Disponível em: <http://www.scielo.br/pdf/se/v24n3/05.pdf>. Acesso em: 10 jul. 2017.

ASSUNÇÃO, C. Q. S.; ASSIS, R. M.; CAMPOS, R. H. F. Belos, sadios e normais: as representações sociais dos corpos infantis na Revista Pais \& Filhos (1968-1977). Rev. Bras. Ciênc. Esporte, Florianópolis, v. 34, n. 3, p. 571-587, jul./set. 2012. Disponível em: <http://www.revista.cbce.org.br/index.php/RBCE/article/view/1170>. Acesso em: 10 maio 2017.

BARDIN, L. Análise de conteúdo. São Paulo: Edições 70, 2011.

BEGGIATO, C. L.; SILVA, S. A. P. S. Educação Física Escolar no ciclo II do ensino fundamental: aspectos valorizados pelos alunos. Motriz, Rio Claro, v. 13, n. 2, p. 29-35, maio/ago. 2007. Disponível em:

<http://www.periodicos.rc.biblioteca.unesp.br/index.php/motriz/article/view/816/753>. Acesso em: 10 maio 2017.

BOURDIEU, P. Questões de sociologia. Lisboa: Fim de século, 2003.

Razões Práticas: Sobre a teoria da ação. 9. ed. São Paulo: Papirus. 1996.

CASTORIADIS, C. A instituição imaginária da sociedade. Rio de Janeiro: Paz e Terra, 1982.

CHARTIER, R. A história cultural: entre práticas e representações. Lisboa: Difel, 1990.

ESPÍRITO-SANTO, G.; MOURÃO, L. A auto-representação da saúde dos professores de educação física de academias. Rev. Bras. Cienc. Esporte, Campinas, v. 27, n. 3, p. 39-55, maio 2006. Disponível em: <http://revista.cbce.org.br/index.php/RBCE/article/viewFile/73/79>. Acesso em: 10 maio 2017.

FERRAZ, A. P. C. M.; BELHOT, R. V. Taxonomia de Bloom: revisão teórica e apresentação das adequações do instrumento para definição de objetivos instrucionais. Gest. Prod., São Carlos, v. 17, n. 2, p. 421-431, 2010 . Disponível em: $<$ http://www.scielo.br/scielo.php?script=sci_arttext\&pid=S0104530X2010000200015\&lng=en\&nrm=iso>. Acesso em: 02 jun. 2017.

FERREIRA, N. S. A. As pesquisas denominadas "estado da arte". Educ. Soc., Campinas, v. 23, n. 79, p. 257-272, ago. 2002. Disponível em: 
$<$ http://www.scielo.br/scielo.php?script=sci_arttext\&pid=S0101$73302002000300013 \& \operatorname{lng}=e n \& n r m=i s o>$. Acesso em: 01 mar. 2017.

GIL, A. C.. Métodos e técnicas de pesquisa social. 6. ed. São Paulo: Atlas, 2008.

GUTIERREZ, G. L.; ALMEIDA, M. A. B.; MARQUES, R. F. R. Apropriação das ciências humanas pela Educação Física: análise dos processos de classificação no Brasil entre os anos de 2007 e 2012. Rev. Bras. Educ. Fís. Esporte, São Paulo, v. 30, n. 4, p. 937-49, out./dez. 2016. Disponível em: <http://www.scielo.br/pdf/rbefe/v30n4/1807-5509-rbefe-30-040937.pdf>. Acesso em: 15 jul. 2017.

HARDY-VALLÉE, B. Que é um conceito? São Paulo: Parábola, 2013.

JAPIASSU, H. Interdisciplinaridade e patologia do saber. Rio de Janeiro: Imago, 1976.

JODELET, D. Folies et Représentations Sociales. Paris: PUF, 1989.

Representações sociais: um domínio em expansão. In: JODELET, D. (Org.). As representações sociais. Rio de Janeiro: UERJ, 2001. p. 17-44.

Sobre o movimento das representações sociais na comunidade científica brasileira. Temas em Psicologia, Ribeirão Preto, v. 19, n. 1, p. 19-26, jul. 2011. Disponível em: <http://pepsic.bvsalud.org/scielo.php?script=sci_arttext\&pid=S1413-389X2011000100003>. Acesso em: 12 mar. 2017.

LAZZAROTTI FILHO, A.; SILVA, A. M.; MASCARENHAS, F. Transformações contemporâneas do campo acadêmico-científico da Educação Física no Brasil: novos habitus, modus operandi e objetos de disputa. Movimento, Porto Alegre, v. 20, n. esp., p. 67-80, 2014. Disponível em: 〈http://seer.ufrgs.br/index.php/Movimento/article/view/48280〉. Acesso em: 15 jul. 2017.

MELLO, A. S. et al. Representações sociais sobre a educação física na educação infantil. Rev. Educ. Fis/UEM, Maringá, v. 23, n. 3, p. 443-455, jul./set. 2012. Disponível em: <http://www.periodicos.uem.br/ojs/index.php/RevEducFis/article/view/12684〉. Acesso em: 10 maio 2017.

MINAYO, M. C. S. O desafio da pesquisa Social. In: MINAYO, M. C. S. (Org.). Pesquisa Social: teoria, método e criatividade. 31. ed. Petrópolis: Vozes, 2012.

MOLINA, R. M. K.; SILVA, L. O.; SILVEIRA, F. V. Celebração e transgressão: a representação do esporte na adolescência. Rev. bras. Educ. Fís. Esp, São Paulo, v. 18, n. 2, p. 12536, abr./jun. 2004. Disponível em: 〈http://www.revistas.usp.br/rbefe/article/view/16555>. Acesso em: 10 maio 2017.

MOSCOVICI, S. Prefácio. In: GUARESCHI, P. A.; JOVCHELOVICH, S. (Org.). Texto em Representações Sociais. 2. ed. Petrópolis: Vozes, 1995. p. 07-16.

MOSCOVICI, S. Representações sociais: investigações em psicologia social. 11. ed. Petrópolis: Vozes, 2015. 
OSÓRIO, Y.; ASSIS, M. R.; PEREIRA, G. A representação social de estudantes de educação física sobre o campo profissional. Pensar a Prática, Goiânia, v. 16, n. 2, p. 533-549, abr./jun. 2013. Disponível em: <https://www.revistas.ufg.br/fef/article/view/17620>. Acesso em: 10 maio 2017.

PEREIRA, G. M. S.; MAZZOTTI, T. B. Representações sociais de Educação Física por alunos trabalhadores do ensino noturno. Motriz, Rio Claro, v.14, n.1, p.53-62, jan./mar. 2008. Disponível em: <http://www.periodicos.rc.biblioteca.unesp.br/index.php/motriz/article/view/1259/1595>. Acesso em: 10 maio 2017.

RETONDAR, M. J. As representações sociais do ato pedagógico dos professores de educação física que atuam no ensino fundamental no município do Rio de Janeiro. Motrivivência, Florianópolis, v. 21, n. 32/33, p. 211-229, jun./dez. 2009. Disponível em: <https://periodicos.ufsc.br/index.php/motrivivencia/article/view/2175-8042.2009n3233p211>. Acesso em: 10 maio 2017.

ROMANOWSKI, J. P.; ENS, R. T. As pesquisas denominadas do tipo "estado da arte" em educação. Revista Diálogo Educacional, Curitiba, v. 6, n. 19, p. 37-50, set./dez. 2006. Disponível em: <http://www.redalyc.org/articulo.oa?id=189116275004>. Acesso em: 01 mar. 2017.

RORTY, R. Contingência, ironia e solidariedade. Lisboa: Editorial Presença, 1994.

SÁ, C. P. A construção do objeto de pesquisa em Representações Sociais. Rio de Janeiro: EDUERJ, 1998. 110 p.

SILVA, A. C. S. et al. Representações Sociais de adolescentes sobre ser saudável. Rev. Bras. Ciênc. Esporte, Florianópolis, v. 36, n. 2, p. 397-409, abr./jun. 2014. Disponível em: <http://www.scielo.br/pdf/rbce/v36n2/0101-3289-rbce-36-02-00397.pdf>. Acesso em: 10 maio 2017.

SPINK, M. J. P. Representações Sociais: questionando o estado da arte. Psicologia \& Sociedade, Belo Horizonte, v. 8, n. 2, p. 166-186, jul./dez. 1996.

VALENTIN, R. B.; COELHO, M. Sobre as escolinhas de futebol: processo civilizador e práticas pedagógicas. Motriz, Rio Claro, v. 11, n. 3, p. 185-197, set./dez. 2005. Disponível em: <http://www.rc.unesp.br/ib/efisica/motriz/11n3/12VBR.pdf>. Acesso em: 10 maio 2017.

VASCONCELOS, F. F.; CAMPOS, P. H. F. Ancoragem da representação social da Educação Física escolar nas abordagens teóricas da educação física. Motrivivência, Florianópolis, v. 26, n. 43, p. 164-182, dez. 2014. Disponível em: <https://periodicos.ufsc.br/index.php/motrivivencia/article/view/21758042.2014v26n43p164/28117>. Acesso em: 10 maio 2017. 
Endereço para correspondência:

diegopetyk@uol.com.br

Diego Petyk de Sousa

Universidade Estadual de Ponta Grossa

Departamento de Educação Física

UEPG/Campus Uvaranas - Bloco G

Avenida General Carlos Cavalcanti, 4748 Ponta Grossa PR 